\title{
Legislación penal nicaragüense con equidad de género para lograr la igualdad real entre mujeres y hombres: principales problemáticas
}

\author{
Victoria del Carmen López Urbina \\ Jueza especializada en violencia, Nicaragua \\ vickylour@hotmail.com
}

Fecha de recibido: Enero 2018 / Fecha de aprobación: Junio 2018

\section{Resumen}

A partir de la ilustración, la lucha por la igualdad implica que los varones y mujeres deben recibir los mismos tratos y beneficios, lo que se transformó en el horizonte normativo y ético del feminismo, en virtud que las desventajas de la mujer empezaron a ser parte en la población. Hoy en día, pese a esta lucha y grandes logros, aún persisten las desigualdades entre hombres y mujeres. Así la lucha por la igualdad no ha permanecido estática, se ha ido enriqueciendo y reformulando a través del tiempo y se ha incluido en la legislación de diferentes países incluyendo Nicaragua. En este trabajo se analiza la inclusión del principio de igualdad en la legislación nicaragüense, inspirador del resto de los derechos fundamentales en el ámbito penal. Asimismo, será prioridad analizar el principio de igualdad real y material y sus principales problemas.

\section{Palabras Clave}

Equidad de género/ feminismo/igualdad formal/ igualdad real/violencia de género

\section{Abstract}

From the illustration, the struggle for equality implies that men and women should receive the same treatment and benefits, which became the normative and ethical horizon of feminism, since the disadvantages of women began to be part of the population. Today, despite this struggle and great achievements, inequalities between men and women persist. Thus the struggle for equality has not remained static, has been enriched and reformulated over time and has been included in the legislation of different countries including Nicaragua, so I will develop the inclusion of the principle of equality in Nicaraguan law, inspiring Of the rest of the fundamental rights in the criminal area. It will also be $a$ priority to analyze the principle of real and material equality and its main problems.

Gender equality / feminism/ formal equality / real equality/Violence against women 


\section{Tabla de contenido}

Introducción. I. Concepto histórico de igualdad; I. Igualdad formal en la Constitución Política.

2. Principio de no discriminación; 3. De la diferencia a la desigualdad. II. Igualdad de género en la ley. I. Diferencia e igualdad; 2. Aparición del feminismo. 3. Juicio de razonabilidad. III. Igualdad formal para igualdad real; I. La igualdad entre hombres y mujeres. 2. La fórmula de igualdad. Igualdad como concepto valorativo. IV. Prohibición de discriminación en la Constitución Política de Nicaragua. I. El principio de igualdad como principio inspirador del ordenamiento jurídico nicaragüense. 2. Principio de igualdad en las convenciones internacionales. V. El principio de igualdad material como finalidad del trato desigual. I. Políticas de Estado. 2. ¿Se ha conseguido la igualdad real de derecho entre mujeres y hombres, una vez reconocida la igualdad legal?. 3. Espejismo de la igualdad. VI. Principales problemas para alcanzar una igualdad real con equidad de género en el derecho penal. I. Factores que inciden en la desigualdad de género en el derecho penal nicaragüense. 6. Resultados y aportes. Lista de referencias.

\section{Introducción}

La igualdad es uno de los principios invocados con mayor frecuencia en el Derecho Internacional de los Derechos Humanos. Una de sus manifestaciones es la igualdad en la aplicación de la ley. Durante los últimos cuarenta y cinco años, organismos internacionales se han abocado, en forma continua, al desarrollo y promulgación del derecho de igualdad; desde la Revolución Francesa hasta nuestros días.

Aunque la igualdad es un tema dominante y recurrente en ordenamiento jurídico nicaragüense, la norma no está contemplada en la totalidad de las diversas fuentes del Derecho internacional de manera única y unificada. Asimismo, en la Constitución política de Nicaragua y en la legislación especializada contra la violencia hacia las mujeres se proclama formalmente el derecho de igualdad y no discriminación como un derecho fundamental de todos, sin embargo persisten importantes obstáculos en la materialización efectiva de esa igualdad. Así, se vislumbra un distante reconocimiento desde el texto legal hasta su aplicación por quienes están llamados a reconocer ese derecho, es decir, por los órganos que ejercen jurisdicción y particularmente los tribunales de justicia. En el proceso de aplicación, el significado de la igualdad ante la ley ha presentado deficiencias, en muchos casos ineficacia, principalmente cuando se trata de su aplicación en el marco de la perspectiva de género.

Uno de los grandes problemas que enfrentan los jueces surge cuando tienen que tratar idénticamente situaciones análogas y sólo hacerlo en forma diferente cuando no se asimilen, en cuyo último caso, poseen la carga de argumentar, para justificar ese tratamiento distinto, para evitar alguna manifestación de inconstitucionalidad.

Otro de los problemas se pone de manifiesto cuando los jueces omiten realizar un juicio de valor, debido a que la igualdad es relativa e histórica y por lo tanto relacional. Consecuentemente, se pierde la posibilidad de hacer una distinción entre la igualdad formal y la igualdad real. En particular, cuando corresponde aplicar igualdad con perspectiva de género, la cual requiere valorar condiciones históricas, socio-culturales y políticas. De ahí que, también debe expresarse 
en un anclaje contextual en el marco del feminismo, la lucha por el reconocimiento de los derechos de la mujer a ser tratada en un plano de igualdad para lograr una autonomía social, política y económica.

A partir de estos elementos, este trabajo tiene como objetivo ofrecer un análisis de la igualdad en la legislación penal nicaragüense con equidad de género, sus perspectivas para lograr una igualdad real entre mujeres y hombres, los principales problemas de aplicación, ya que pese a la existencia de leyes y políticas del Estado que promueven la igualdad, se identifican deficiencias notables. En definitiva, determinar cuáles son las principales problemáticas en la realización del derecho de igualdad y no discrimnación y sus posibles caminos de solución son el objeto de estudio de la presente investigación.

Para la realización de los objetivos propuestos se realizó una amplia revisión bibliográfica sobre el tema, la cual se detalla al final de este trabajo.

Para la realización de la investigación se utiliza el método científico con el que se garantiza el análisis de la construcción jurídica sobre el principio de igualdad y su aplicación desde una perspectiva de género.

El método de análisis histórico-lógico que permitirá identificar los antecedentes históricos de la igualdad de género, su origen, manifestación, regulación jurídica y los principales problemas en su aplicación.

En este mismo orden, con el método exegético-analítico, se analizará el alcance del ordenamiento jurídico en materia de igualdad de género, cuya aplicación será objeto estudio en esta investigación.

También se ha realizado una revisión de la bibliografía especializada en la materia vinculada con el objeto de la investigación.

\section{Concepto histórico de Igualdad}

El concepto de los hombres como iguales ante la ley ha sido incluido por la Declaración de Derechos Humanos en 1948. Esto ha servido de bandera para las luchas sociales por parte de las mujeres en favor de la inclusión, como es el caso del derecho al voto femenino. La idea de igualdad es un producto histórico, cuya definición ha venido cambiando con el tiempo. Algunos creen que su origen es religioso, secularizada por la ilustración y generalizada sobre diferentes áreas por la revolución democrática de los dos últimos siglos.

En esta línea de ideas, Herranz Gómez (2006) afirma:

Así, tener derechos ha sido una conquista histórica, la gran conquista de la humanidad. Lo que hoy consideramos derechos humanos, derechos de toda la humanidad, son exigencias éticas basadas en un determinado modo de entender la humanidad: el concepto de persona, y el de dignidad que la define. Aunque desde la Antigüedad la humanidad ha pretendido tener derechos como una aspiración a tener una vida realmente humana y digna, considerada como algo valioso, es en la Modernidad cuando se van reconociendo nuevas dimensiones de la dignidad humana y consecuentemente empiezan a reclamar nuevos derechos para tratar de preservarla. El proceso histórico de esta afirmación de derechos, relacionado con la aparición del Estado moderno y un nuevo modelo político, ha sido lento y difícil, iniciándose en el período ilustrado y culminando, por el momento, en la Declaración Universal de Derechos Humanos, que nos es más que una síntesis y concreción de estos derechos (p. 24).

La igualdad es resultado de una lucha social, no es un resultado natural, sino un resultado de luchas históricas con el fin que hombres y mujeres sean reconocidos como tal en la Constitución 
Política de cada nación o país donde se ha ganado esta lucha. De tal forma que la igualdad como derecho es producto de la construcción humana y de acuerdo a las relaciones socio culturales de las personas, lo que implica también que el concepto de igualdad ha venido cambiando en la medida que las luchas por otros derechos también son exigidos en la sociedad y se ha obtenido su reconocimiento, tal es el caso del derecho a la dignidad y la libertad. La libertad, entendida, como igualdad de oportunidades que permite el desarrollo de la autonomía y potencialidad de las personas, evidentemente es un derecho inhalienable de la mujer. Aunque sabemos, que el principio de igualdad se manifiesta dentro de un contexto histórico determinado, según las situaciones sociales culturales de cada época y país. En el caso de Nicaragua caracterizado por una sociedad eminentemente machista, permeada de un patriarcado de consentimiento y de un sexismo, del que aún muchas mujeres participan por no estar empoderadas y concientizadas de lo que significa la igualdad.

Aun así, históricamente las mujeres también han venido luchando por ser reconocidas, pretendiendo que la dignidad y libertad del hombre sea extensiva a la mujer como sujeto de derechos humanos.

En este sentido el principio de igualdad sigue un proceso histórico cuyo origen se manifiesta en la Declaración Universal de los Derechos Humanos de 1984, que se concibe como un logro de todas las naciones, en la cual deben reconocerse las circunstancias sociales e históricas en que se promulgó tal Declaración, considerando por tanto que no existe abstracción en la igualdad.

Ese contexto histórico social también se manifiesta en la mujer, vemos por ejemplo, a partir de los años cincuenta, la mujer emerge como un ciudadano que denuncia la desigualdad de género, que proviene de una constante discriminación que se manifiesta cuando las diferencias y los estereotipos culturales atribuidos a cada sexo se naturalizan, sin identificar, ni reconocer su origen histórico y social y es precisamente lo que lleva a la mujer a la lucha por la igualdad y equidad de género.

Así, para la CEPAL (1993)

Si bien desde los años setenta las mujeres de la región han tenido una amplia y visible participación en el movimiento de defensa de los derechos humanos, esto no significó que hayan llevado necesariamente a su seno reivindicaciones de género. Recién a fines de los años ochenta surgen con fuerza la conciencia y la práctica de las mujeres como sujetos de derecho, que comienzan a cuestionar la visión esencialista de las jerarquías sociales y la vivencia de su subordinación como normalidad. En este contexto, sus demandas en torno a los derechos humanos también son una consecuencia de sus demandas de construcción de nuevas formas de ejercicio de la ciudadanía y de su deseo de acceder a ésta en condiciones de igualdad, en virtud del principio según el cual el derecho básico es el "derecho a tener derechos" (p. 13).

La subordinación de la mujer se muestra en diferentes contextos, ya sea en el económico o en el simbólico. En el económico cuando no se reconocía a la mujer el derecho a recibir el mismo salario que los hombres y se les negaba su participación en las actividades políticas, y en contexto simbólico cada vez se promueve la imagen de hombre como sujeto y la mujer como objeto. Desde el androcentrismo donde el hombre es el centro del universo hasta el patriarcado de consentimiento donde la mujer se somete voluntariamente a ser subordinada por el hombre.

Dentro de ese marco, la desigualdad ha estado presente desde el principio de los tiempos, y los pueblos han mantenido una lucha constante contra ella con muy pocos resultados hasta la Revolución Francesa, cuando se alcanzó su integridad como concepto y empezó a ser un valor defendido globalmente, bajo el lema "libertad, igualdad y fraternidad", aunque esto aún no incluía a las mujeres, porque era el resultado de la lucha de clases sociales entre hombres. 
De Puelles Benítez (2012) afirma:

El triple emblema de la Revolución Francesa sigue configurando la identidad de la democracia y ofreciendo su mejor definición, quizás porque en esa tríada sus elementos nutren de una misma savia, que es la aspiración perenne de las personas a vivir como seres libres, iguales y solidarios. Quizá también porque el lema "libertad, igualdad y fraternidad" convergen inextricablemente principios de naturaleza moral, social y política (p. 120).

En este sentido la igualdad constituye el resultado de una lucha contra el perjuicio, el fundamento del individuo y de la democracia. Sin embargo su construcción ha sido dificultosa precisamente por esos perjuicios, privilegios, muchas situaciones que han justificado la desigualdad entre los hombres.

En el caso de la Revolución Francesa vemos que se promulgan la libertad, igualdad y fraternidad, en segundo lugar la igualdad, pero cuando se establece la Declaración de los Derechos del Hombre no rige para la mujeres, sino para los propietarios, solo regía para los que son propietarios de la tierra, hay una larga lucha para ir haciendo la igualdad, en la medida que se va haciendo más inclusiva se va haciendo más amplio el concepto de igualdad, y por ende se va haciendo más democracia.

\section{Alvar, Robledo, Martos y Rodríguez sostienen:}

La Revolución Francesa (1789) y las demás revoluciones liberal-burguesas plantearon como objetivo central la consecución de la igualdad jurídica y de las libertades y derechos políticos. Pronto surgió la gran contradicción que marcó la lucha del primer feminismo: las libertades, los derechos y la igualdad jurídica que habían sido las grandes conquistas de las revoluciones liberales no afectaron a la mujer. Los "Derechos del Hombre y del Ciudadano" que proclamaba la revolución francesa se referían en exclusiva al "hombre" no al conjunto de los seres humanos (2006, p. 292).

Pues, pese a que se promulgan los Derecho Humanos, estos a lo largo de la historia han venido siendo infringidos, sin respeto, ni valor alguno. Su infracción ha traído consecuencias negativas como lo es el sometimiento de los pueblos, pero cuando de género se trata, hasta el momento que se promulga esta Declaración como la mujer no había sido reconocida como sujeto de derechos humanos, seguía siendo víctima de la esclavitud, maltratos y sometimientos. Por lo tanto, la mujer continúa su lucha por la igualdad.

Labiano, Robledo, Martos y Rodríguez (2006) aseguran:

A partir de aquel momento en Europa Occidental y Norteamérica se inició un movimiento, el feminismo, que luchó por la igualdad de la mujer y su liberación. Durante este período, el principal objetivo del movimiento de las mujeres fue la consecución del derecho de voto. Nacía así el movimiento sufragista... La autora teatral y activista revolucionaria Olimpia Gouges (1748-1793) fue la protagonista de la contestación femenina. En 197Ipublicó la Declaración de Derechos del Hombre y del Ciudadano aprobada por la Asamblea Nacional en agosto de 1789. El programa de Olimpia de Gouges era claro: libertad, igualdad y derechos políticos, especialmente el derecho al voto, para las mujeres (p.292).

La negación de los derechos de la mujer da surgimiento a un conjunto heterogéneo de movimientos políticos, culturales, económicos y sociales cuyo objetivo es la liberación de las mujeres y el reconocimiento de sus derechos. Los movimientos feministas tuvieron una significativa influencia, logrando la igualdad ante la ley y el voto femenino, entre otros y su inclusión en el texto constitucional. Surge entonces la teoría feminista cuya influencia ha logrado importantes cambios jurídicos en materia de género y principalmente en materia de igualdad de género. 
Villacorta Mancebo (2006) afirma:

En este sentido ha podido afirmarse que la realización práctica de igualdad queda en amplia medida supeditada a la cultura espiritual de cada época y espacio territorial, toda vez que si ciertamente el significado del mismo está determinado por el orden constitucional - en la medida de lo posible-, también lo va a estar, y no en menor grado, por la atmósfera política, social y jurídica de cada Estado de otra parte, sin negar la buena argumentación expuesta por quienes insisten acerca de la naturaleza intrínsecamente relacional del derecho fundamental a la igualdad, no se puede dejar de otorgar relieve al hecho de que en la cultura occidental moderna la igualdad aparece históricamente como un valor ético moral de carácter fundamental y autónomo, diferenciable, por lo tanto, de los valores tutelados a través del reconocimiento de los derechos de libertad o del resto de los derechos humanos y fundamentales en general (p. 27).

Desde el punto de vista de la dogmática constitucional del Estado social, la determinación del concepto de igualdad puede considerarse no sólo muy difícil tarea sino propiamente el quehacer más difícil, esto es, la tarea de expresar cuál es en realidad el significado de que a través del principio de igualdad tanto el legislador como el aplicador de la norma que se encuentran vinculados a la realización práctica de la igualdad.

El paradigma sobre el cual se han aplicado los catálogos de derechos ha consistido en un titular de derechos que se construye culturalmente con características muy particulares.

Herranz Gómez (2006) afirma:

En el siglo XVII surge un nuevo modelo político llamado contractualista, basado en la idea de igualdad para todos los miembros del Estado y en su participación política como integrantes del mismo. Se entendía que para que una sociedad esté legítimamente constituida, debía asentarse sobre la igualdad de los seres humanos, desechando cualquier privilegio por nacimiento (p. 23).

Luego de las luchas feministas y sus importantes logros, surge un nuevo modelo basado en una idea de igualdad, sin exclusión alguna. No deben pesar más mandatos y prohibiciones que limiten el acceso de la mujer a activos económicos, sociales y culturales.

En este sentido, López Chocero y Sachis Vidal señalan que la aplicación del concepto de género al Derecho ha marcado la transición de las leyes de igualdad clásicas a las leyes de igualdad modernas. De este modo explican, citando a Gil Ruis (2012) que este proceso se ha producido en tres etapas:

...la primera se centraba en la igualdad de derechos y en la igualdad de trato ante la ley; la segunda, que se centró en la acción positiva y en las medidas específicas para las mujeres; $y$ una tercera que pretende, mediante la "perspectiva de género", incorporar cambios sustanciales de igualdad efectiva inter-géneros, implicando en esta tarea a los hombres. En otras palabras, se ha pasado de la lucha por la lgualdad formal (la igualdad política, la igualdad ante la ley y la igualdad de derechos), punto cardinal del Estado Liberal, a la lucha por la igualdad de oportunidades, sin olvidarnos de la lucha por la igualdad de hecho o sustancial, punto cardinal del Estado Social, en una dura y agotadora carrera de aciertos y desaciertos (2016, p. 397).

I. Igualdad formal en la Constitución Política.

En el contexto de la dogmática jurídica sobre los derechos fundamentales, el problema del significado del principio general de igualdad ocupa un lugar central y problemático a la hora de su aplicación e interpretación, surgiendo dudas y perdiendo la orientación. La estructura máxima jurídica de la igualdad, se interpreta en un sentido formal en el actual Estado social que se hace extensivo hasta los jueces al momento de aplicar el arto. 27Cn.

Pérez Portilla (2002) afirma: 
El término "igualdad" tiene una carga retórica considerable, por lo cual, no es de extrañar el uso que se le ha dado a manera de slogan político. Por lo menos, desde la Revolución Francesa, la igualdad ha sido uno de los ideales políticos más importantes y quizá sea hoy en día una de los ideales sociales más controvertidos. Una primera controversia tiene que ver con lo que ha de entenderse por "igualdad"; una segunda tiene que ver con la relación entre "la igualdad y la justicia"; y finalmente, un problema más es el de su extensión, esto es, la determinación de "igualdad de qué" e "igualdad entre quienes" (p. 5).

El Tribunal Constitucional Español en su Sentencia STC 59/2008 de 14 de mayo de 2008, en la cual responde a la cuestión de inconstitucionalidad planteada al artículo 153.I del código penal español en la redacción de este dada por la Ley Orgánica de Protección Integral contra la Violencia de Género, declaró que la igualdad reconocida en el artículo 14 de la Constitución Española no implica una prohibición de trato diferenciado, sino que es compatible con el trato diferenciado cuando: a) la diferencia jurídica persigue un fin legítimo y b) las consecuencias de la diferencia no son desproporcionadas (Larrauri Pijoan, 2009). Este tribunal expone de la siguiente manera por qué a su juicio en este caso la diferencia está justificada:

$Y$ en resumen defiende que la distinta penalidad -el trato diferenciado- está justificada debido a las 'altísimas cifras en torno a la frecuencia de una grave criminalidad que tiene por víctima a la mujer y por agente a la persona que es o fue su pareja' (por tanto, finalidad legítima de la diferencia por motivos de prevención de los comportamientos agresivos).

Una vez confirmada la existencia de una finalidad legítima, el TC procede a examinar si las consecuencias de esta diferenciación jurídica son desproporcionadas. En este caso la argumentación del TC es más sumaria y afirma en síntesis que el desequilibrio 'no es patente y excesivo o irrazonable', puesto que la diferencia se produce: i) sólo en el mínimo de la pena; ii) hay una pena alternativa de trabajo en beneficio a la comunidad que es idéntica en ambos casos; iii) en el supuesto de circunstancias excepcionales la pena puede rebajarse un grado acudiendo al artículo 153.4 (Larrauri Pijoan, 2009, pp. 8-9)

La igualdad formal que se traduce en el artículo 27 constitucional en el derecho de igualdad ante la ley, no debe ser entendida en términos absolutos, sino que debe considerarse la posibilidad de dar un tratamiento desigual a diversos sujetos del derecho. Tal es el caso de las víctimas de violencia de género que se encuentran en condición de vulnerabilidad por razón del género, sin que esta relativización produzca el quebrantamiento de Derechos Humanos y resulte discriminatorio.

La Reglas Básicas de Acceso a la Justicia de las Personas Vulnerables (2002) establece:

La Cumbre Judicial Iberoamericana, dentro del marco de los trabajos de su XIV edición, ha considerado necesaria la elaboración de unas Reglas Básicas relativas al acceso a la justicia de las personas que se encuentran en condición de vulnerabilidad. De esta manera, se desarrollan los principios recogidos en la "Carta de Derechos de las Personas ante la Justicia en el Espacio Judicial Iberoamericano" (Cancún 2002), específicamente los que se incluyen en la parte titulada "Una justicia que protege a los más débiles" (apartados 23 a 34).

En este sentido la igualdad formal debe traducirse en material. La igualdad formal se traduce en el derecho a la igualdad ante la ley. La igualdad material se traduce en el derecho a la no discriminación en las concretas relaciones sociales, evitando las diferencias o desigualdades por razón del género, cuando se trata de violencia de género. 
La igualdad formal no es efectiva sino se traduce en el reconocimiento de la igualdad real o material, obteniendo igual protección de la ley y de acuerdo a las condiciones desiguales en que las mujeres se encuentran frente a la violencia de género y la discriminación por razón del género. En palabras de Fernández de Castro, mientras que la primera es una igualdad en el punto de partida, la segunda "hace referencia a la idea de conseguir ese objetivo en el punto de llegada a través de las medidas y acciones oportunas para conseguir la igualdad real" (2012, p. 80).

La igualdad ante la ley supone el reconocimiento formal por parte de las normas jurídicas del principio de no discriminación tal y como se contempla genéricamente en las normas jurídicas, la que se produce de dos formas distintas:

De una manera implícita: a través de las fórmulas muy repetidas en los textos internacionales y en los textos constitucionales de todos, en el caso de Nicaragua en el arto. 27 del texto constitucional que a la letra dice: "Todas las personas son iguales ante la ley y tienen derecho a igual protección. No habrá discriminación por motivos de nacimiento, nacionalidad, origen, posición económica o condición social"

En la legislación nicaragüense, se ha percibido que muchos jueces, no han aterrizado en el concepto de igualdad, al considerarlo como igualdad de oportunidades en un proceso penal, y no como un trato diferenciado, para lograr la igualdad. Se ha desarrollado una legislación en materia de violencia de género que permite a los jueces dar es trato diferenciado, debiendo considerar en sus resoluciones que la fórmula del arto. $27 \mathrm{Cn}$ prohíbe específicamente cualquier tipo de discriminación por cualquier razón que suponga una infracción o una quiebra del sistema de Derechos Humanos, que esto es extensivo a las mujer, ya que el fin de la norma constitucional es igualdad en el ejercicio de los derechos tanto del hombre como de la mujer, para que esta última sea visibilizada y por ello reconoce los instrumentos internacionales en materia de derechos humanos, que son aplicables en el proceso penal y son recogidos por las leyes especiales, tal es el caso del arto. 5 de la Ley $\mathrm{N}^{\circ} 779$ que reconoce como fuentes de interpretación de la ley las convenciones Belén Do Pará y Cedaw.

Así, el arto. 46 Cn reconoce los Convenios internacionales en materia de Derechos Humanos y establece:

[Convenios internacionales constitucionalizados] En el territorio nacional toda persona goza de la protección estatal y del reconocimiento de los derechos inherentes a la persona humana, del irrestricto respeto, promoción y protección de los derechos humanos y de la plena vigencia de los derechos consignados en la Declaración Universal de los Derechos Humanos; en la Declaración Americana de Derechos y Deberes del Hombre; en el Pacto Internacional de Derechos Económicos, Sociales y Culturales y en el Pacto Internacional de Derechos Civiles y Políticos de la Organización de las Naciones Unidas; y en la Convención Americana de Derechos Humanos de la Organización de Estados Americanos.

Hay una tendencia en la legislación nicaragüense situada contextualmente en el arto. 27Cn de forma general, producto de los tratados internacionales suscritos por Nicaragua en orden de garantizar la plena efectividad del principio de igualdad y no discriminación.

La igualdad ante el poder legislativo supone doble límite al legislador:

I) Un límite de naturaleza subjetiva o de defensa: implica el reconocimiento por parte de las normas jurídica del derecho a la igualdad, permitiendo poner en marcha mecanismos de restablecimiento de la igualdad en casos de quebrantamiento. 
2) Un límite de naturaleza objetiva: significa que el legislador debe crear normas jurídicas que sean respetuosas con el sistema de Derechos Humanos, evitando situaciones discriminatorias o injustificadamente desiguales.

En este contexto la igualdad constitucionalizada supone el reconocimiento y cumplimiento efectivo de las garantías del ciudadano frente a la administración de justicia y frente a terceros. Esto se encuentra en estrecha vinculación con el principio de legalidad, imparcialidad, evitación de trato desigual y no discriminación y que lo encontramos regulado en la Ley $\mathrm{N}^{\circ} 779$ y en el Decreto 43-2014 "Política de Estado" que dan la posibilidad de defender la igualdad y eso dependerá de cómo el juzgador la aplique y la haga valer en favor de la mujer y el hombre en un marco de la igualdad y desde la perspectiva de género.

Sala, Ballester, Bañó, Embid y Goerlich afirman que:

El reflejo del valor igualdad en la constitución es particularmente trascendental en la medida que la peculiar naturaleza le convierte en un derecho relacional o conexo que no tiene autonomía propia, sino que integra todos y cada uno de los derechos fundamentales $y$, por extensión, las diferentes relaciones jurídicas concretas y el conjunto de disposiciones que integran el ordenamiento jurídico (2008, p. 107).

En el ámbito penal el principio de igualdad se ve reflejado en el principio de legalidad en los delitos y las penas y con el resto de las garantías normativas. En el caso de la Ley $\mathrm{N}^{\circ} \mathbf{7 7 9}$ "Ley Integral Contra la Violencia hacia las Mujeres y de Reformas a la Ley $N^{\circ} 64$ I, "Código Penal”, lo vemos reflejado en el arto. 4 literal a) acceso a la justicia.

Las instituciones del Estado, operadores del sistema de justicia y las autoridades comunales deben garantizar a las mujeres, sin ninguna distinción, el acceso efectivo a los servicios y recursos que otorgan, eliminando todo tipo de barreras y obstáculos de cualquier índole que impidan el acceso.

El arto. I del Código Procesal Penal (en adelante, CPP) posee un listado de diecisiete principios que regulan el proceso penal, cuya primacía es el respeto a los derechos fundamentales.

El principio de igualdad constitucional ha sido retomado en la Ley $\mathrm{N}^{\circ} 779$. Sin embargo, el talón de Aquiles se encuentra en la materialización de la igualdad, de ahí la distinción entre la igualdad formal y la real o material.

La igualdad no solo deber ser formal, sino objetiva, reconocer la identidad de los iguales y la diferencia entre los desiguales, así pasar de la generalidad abstracta a la generalidad concreta, que permita diferente normación a supuestos distintos, tal es el caso del género, donde el trato diferente sea justificado, una igualdad material, igualitaria y no cuantitativa, para lo cual no basta que los jueces como administradores de justicia conozcan el concepto, sino que sean conscientes de la relevancia socio jurídica de su validez y de la importancia de vivirla en un contexto socio cultural machista.

Sobre esta línea Bautista (2002) agrega:

La igualdad Real o Material. Según esta concepción, lo importante es la condición real de las personas. Lo que se persigue es colocar a todos/as en condiciones materiales de igualdad y no sólo al nivel de reconocimiento formal. El logro de la igualdad real muchas veces requerirá el trato desigual, para lograr un resultado igual. Es decir, para eliminar los desniveles reales en las situaciones de vida o en el acceso a recursos, oportunidades, bienes o servicios en la sociedad, habrá que tratar a las personas desigualmente situadas en forma diferente. Esta es una vía por las que se pueda transformar muchas situaciones 
de injusticia. Plantean las autoras, que ni la igualdad formal ni la material o real son de por sí suficientes para lograr un trato justo a las personas. Muchas veces el trato justo requiere que se trate a cada cual según sus particulares circunstancias. Es en este sentido que se emplea el término equidad. No se trata de "igualar" a nadie, sino de proveer el trato que las condiciones particulares de cada quien requieran para satisfacer sus necesidades singulares $o$ atender a sus reclamos especiales (p. 18).

Aunque de alguna manera el paradigma de la igualdad, es decir, la noción de que la justicia se realiza tratando a todas y todos por igual, está siendo superado por una nueva propuesta que plantea la necesidad de valorar las diferencias. Esto significa que hay que aceptar las diferencias entre personas y grupos y que estas diferencias pueden ser positivas y deberían ser respetadas. Las diferencias deben ser tomadas en cuenta, no para oprimir y subordinar, sino para potenciar y propiciar el desarrollo personal.

Los hombres y mujeres deben ser iguales, respetando el derecho de igualdad en cuanto humanos y el derecho a la diferencias según las condiciones específicas de cada persona.

La igualdad formal garantiza legalmente los derechos humanos, supone la prohibición legal de discriminación por razón de sexo entre otras. Igualdad como un principio opuesto a la opresión, principio moral de una igual libertad como condicionante para la autonomía de las mujeres. Empero su aplicación para que sea efectiva tiene que ser real, estructural, reconocer a cada individuo su igualdad al derecho a la libertad, en el caso de la mujer en su derecho a la autonomía, la igualdad debe ser para los fuertes y paras los débiles y vulnerables, corresponde a las autoridades judiciales que conocen de las hechos reconocer y considerar en sus resoluciones en materia de género que la igualdad implica una protección a las mujeres sin distinción y requiere que esta protección sea accesible para todas las personas en la situación descrita en la norma jurídica. En el caso de Nicaragua debe considerarse la Ley $\mathrm{N}^{\circ} 779$ y las fuentes de interpretación que regula el arto. 5 de esta Ley como lo son las Convenciones en materia de género:

a) La Convención para la eliminación de todas las formas de discriminación contra la mujer; $y$

b) La Convención interamericana para prevenir, sancionar y erradicar la violencia contra la mujer.

\section{Identidad y Semejanza en materia de igualdad}

Los términos igualdad, identidad y semejanza no son sinónimos, cuando el arto. $27 \mathrm{Cn}$ se refiere a que todos somos iguales ante la ley, no significa que todos sean idénticos, porque identidad y semejanza no son lo mismo, la semejanza identifica una diferencia de las personas u objetos que los separa uno de otro, o bien que los distingue uno del otro, y en el caso de la identidad deben ser iguales sin ninguna diferencia visible, no deben diferir en nada.

El arto. I de la Declaración Universal de los Derechos Humanos establece que: "Todos los seres humanos nace libres e iguales en dignidad y derechos y, dotados como están en razón y conciencia, deben comportarse fraternalmente los unos con los otros". A su vez el arto. 2 de este misma declaración manifiestas que: "Toda persona tiene todos los derechos y libertades proclamados en esta Declaración, sin distinción alguna de raza, color, sexo, idioma, religión, opinión política o de cualquier otra índole, origen nacional o social, posición económica, nacimiento o cualquier otra condición".

Hablar de igualdad entre hombres y mujeres, no se trata de una igualdad idéntica. Los seres humanos se definen como seres diferentes, en virtud que aunque forman parte de una sociedad en la que existen semejanzas, también se establecen diferencias raciales, culturales y religiosas, e igual por razón de género. 
Así, Jiménez de Barro (1992) considera:

El problema, por lo tanto, no está en la igualdad de dignidad-que a esta altura de la historia nadie discute-, sino más bien en la "igualdad-diferenciada", es decir, en la identidad y luego en las oportunidades que la mujer tiene para, desde su igualdaddiferenciadas, participar y tener acceso a cargos directivos de diversa naturaleza, desde donde y pueda gobernar, conducir, influir. Entretanto, en el tema de la identidad habría, en mi opinión, a lo menos dos posiciones. Una que acentúa "lo masculino" como un atributo exclusivo del varón y "lo femenino" como atributo exclusivo de la mujer; y otra, para que "lo masculino y lo femenino" se encuentren presentes en hombres y mujeres $(p, 14)$.

Las ideas expuestas nos llevan a considerar que deben atenderse las características particulares de hombres y mujeres. La identidad se define a partir del reconocimiento de las diferencias individuales, lo que estará marcado por el género, porque se ha condicionado a hombres y mujeres a partir de la forma de percibir y vivir la vida.

El punto de partida inicial fue la invisibilidad de las mujeres como actores sociales e históricos, y que "mujer", "hombre", "feminidad" y "masculinidad" son construcciones históricas y culturales. Esta idea es la que resultó central para la conceptualización de "genero" como relación de poder desigual entre hombres y mujeres (Fernández et al., 2006).

De tal manera que la identidad de género es resultado de la relación que existe entre la subjetividad, la identidad y la condición histórica de cada sujeto, la identidad masculina o femenina se define a partir de los determinantes biológico, psicológico y social, considerándose significativamente que estos elementos son el reflejo del momento histórico, el contexto y las interrelaciones que tiene cada individuo a lo largo de la historia personal.

De acuerdo a la identificación como hombres y mujeres cada sujeto expresara su feminidad o masculinidad, y concebirán el mundo de acuerdo a las creencias y necesidades condicionadas por roles masculinos o femeninos mediante los cuales expresaran sus concepciones de género.

Asimismo, se producen los estereotipos o mitos que convierten a la mujer en una persona discriminada, dándole roles de maternidad, cuido de los hijos y el hogar en completa subordinación al hombre. Como expresa Esquembre Valdés, "el concepto género sirve para explicar la dimensión social y política que se ha construido sobre el sexo biológico" (2010, p. 52). Ser mujer, agrega esta autora, "no se reduce sólo a estar caracterizada por tener un sexo femenino sino que significa también estar sujeta a una serie de prescripciones normativas y se asignación de espacios sociales asimétricamente distribuidos” (2010, p. 52).

De tal manera que hombres y mujeres son iguales no idénticos, ya que la igualdad supone correspondencia en las condiciones sociales y de derechos humanos, que exige que hombres y mujeres reciban un trato igualitario, es un elemento normativo, debiéndose entender que la igualdad es una relación de equivalencia, en el sentido que los sujetos tienen el mismo valor, y precisamente por ello son iguales.

Siempre debe considerarse que al hablar de equidad de género, nos referimos a la justicia en el tratamiento de hombres y de mujeres, traducida también en igualdad de derechos y garantías en el proceso penal y en la autonomía de la mujer en ámbito económico, social y político, y en la toma de decisiones.

Ahora bien, para que exista el trato igualitario se debe realizar un análisis comparativo a la hora de valorar el reconocimiento del principio de igualdad y considerar los obstáculos que tiene la mujer en el acceso a la justicia y la materialización de la igualdad real. 
Pérez Portilla (2002) afirma:

El término "igualdad" (griego, isotes: latín, aequitas, aequalitas: fránces, égalit; alemán. Gleicheheil: ingles equality) se refiere a una relación cualitativa. La igualdad significa correspondencia entre un grupo de diferentes objetos, personas, procesos o circunstancias que tienen las mismas cualidades en por lo menos algún aspecto, pero no en todos, es decir, debe considerarse alguna características en específico. Por lo tanto, debe distinguirse entre igualdad e "identidad". Esta última significa que en un y el mismo objeto corresponde así mismo en todas las características: nombre y descripción, por ejemplo. Asimismo, debe distinguirse entre identidad y "similitud", dado que este último concepto se refiere a una mera aproximación en algún sentido. Por tanto, decir que "los hombres son iguales" no significa que sean idénticos (p. 7).

Si se trata del proceso penal, el judicial debe saber que hombres y mujeres no son idénticos, y que al considerar la igualdad ante la ley, debe realizar juicios de valoración sobre la igualdad en un contexto histórico, socio-cultural y jurídico, siendo partícipes en la desconstrucción de sistemas patriarcales de dominación masculina, que aún se manifiestan en nuestra legislación penal.

Dentro de ese marco, estos juicios de valor deben ser considerados por nuestra legislación nicaragüense, abordados en los textos legales, cuya aplicación sea sometida a supervisión, haciendo un juicio de valoración de circunstancias, identidades, igualdades, desigualdades, condiciones de vulnerabilidad e inclusive como algunos autores consideran debe aplicarse una fórmula que permita justificar en determinado momento las desigualdades en el ámbito de la aplicación de una igualdad estructural.

Autores como Platón y Aristóteles consideran que debe aplicarse una fórmula en la igualdad.

Sobre esa fórmula en la igualdad Pérez Portilla (2002) afirma:

El estudio sobre la igualdad comienza con Platón y Aristóteles: este último, con notable éxito a lo largo de la historia señaló: "parece que la justicia consiste en igualdad, y es así, pero no para todos, sino para los iguales; y la desigualdad parecer ser justo, y lo es, en efecto, pero no para todos, sino para los desiguales". Aristóteles dijo básicamente dos cosas sobre la igualdad que han dominado el pensamiento occidental: I. La igualdad significa: las cosas que son iguales deben tratarse igual y las cosas que son desiguales deben tratarse de manera desigual en proporción a su desigualdad.2. Igualdad y justicia son sinónimos: ser justo, es ser igual, ser injusto es ser desigual (p. 8).

No hay dos personas iguales, la igualdad establece la categoría y al aplicar la igualdad se debe definir criterios determinados para darle sentido a la igualdad y lograr su materialización en el entorno jurídico, tratándose de hombres y mujeres frente al proceso penal, requiere de un juicio de valoración. La igualdad como principio normativo por si solo es vacío y sin significado, corresponde a los juzgadores proceder a la aplicación de fórmulas y estándares que les permitan aplicar justamente el principio de igualdad porque sin igualdad no podría haber justicia y sin justicia no podrían tutelarse los derechos de las mujeres, tampoco podrían reivindicarse esos derechos obtenidos como producto de las luchas de grupos feministas.

Es por lo tanto prioritario para el juzgador contar con esas fórmulas o estándares que garanticen la igualdad real o material y evitar cualquier tipo de discriminación por razón de género, diversidad entre hombres y mujeres que tengan por fin la desigualdad, de manera que se reconozcan las diferencias entre mujeres y hombres como diferencias de género y no sólo sexuales. 


\section{Principio de no discriminación}

Es importante señalar que las Constituciones de la mayoría de los países de la región proclaman el principio de igualdad formal de donde se deriva el derecho a la no discriminación.

Hablar del principio de no discriminación implica hablar de derechos humanos, los cuales son inherentes a todos los seres humanos, sin distinción de alguna nacionalidad, lugar de residencia, sexo, origen nacional o étnico, color, religión, lengua, o cualquier otra condición. Estos derechos son interrelacionados, interdependientes e indivisibles.

Aráuz Ulloa (1999) afirma:

... que cuando se analizan las causas fundamentales de discriminación, la primera que tradicionalmente salta a la vista es aquella que se basa en razones del sexo. Esta ha sido siempre un elemento de discriminación que recogen las leyes, unas veces de manera favorable, otras de forma desfavorable. Ante tal hecho, la opinión pública y la sociedad moderna en general, han tomado consciencia para dar pasos importantes en la línea de los que un día señalara Bobbio (1993:93-94): "la sociedad moderna se enfrenta a una revolución silenciosa y a su vez a la primera revolución incruenta de las historia, es la que conduce a la lenta pero inexorable atenuación, hasta la total eliminación de la discriminación por razón del sexo comenzando por la equiparación de las mujeres a los hombres en la vida familiar, en la sociedad civil y finalmente en las relaciones económicas y políticas atinentes al Estado" (pp. 36-34).

Lo expuesto por Aráuz Ulloa confirma las notorias manifestaciones de discriminación que aun recogen algunas leyes, ya sea favorable o desfavorablemente; aunque se ha legislado positivamente a favor de la equidad de género, prohibiendo expresamente cualquier tipo de discriminación, haciendo referencia también a aquella discriminación por razón del sexo. No se puede pasar por alto el desafío que tienen los jueces de identificar las causas de la discriminación por razón de sexo y eliminar mediante una adecuada aplicación de los preceptos normativos nacionales e internaciones cualquier acto de discriminación que menoscabe el derecho de autonomía de la mujer.

Los derechos humanos universales están a menudo contemplados en la ley y garantizados por ella, a través de los tratados, el derecho internacional consuetudinario, los principios generales y otras fuentes del derecho internacional. El derecho internacional de los derechos humanos establece las obligaciones que tienen los gobiernos de tomar medidas en determinadas situaciones, o de abstenerse de actuar de determinada forma en otras, a fin de promover y proteger los derechos humanos y las libertades fundamentales de los individuos o grupos, sin embargo debemos reconocer que al momento de poner en práctica la norma jurídica se devela una realidad diferente, ya que nos encontramos en una situación real de desigualdad cuando se trata del género o razón del sexo.

Como refieren López Chocero y Sachis Vidal (2016, p. 397), “...la Cuarta Conferencia Mundial sobre la Mujer que se celebró en Beijing en 1995 supuso un punto de inflexion en la consecución de los derechos de las mujeres y el compromiso activo de Gobiernos, instituciones y del resto de la sociedad". Además, como agregan estas autoras, con esta conferencia se trató de poner en marcha mecanismos para lograr la igualdad real, una vez comprobado que no era suficiente con alcanzar la igualdad legal. Tal es así, que el principio de no discriminación se encuentra regulado en textos constitucionales de varios países occidentales, sin embargo persisten algunos indicadores relativos a las brechas de equidad de género en materia de violencia de género, tales como trato diferenciales de las víctimas de violencia en algunos Juzgados o Tribunales Especializados. Por ejemplo, en varios juzgados del país no se ha logrado evitar el contacto de la víctima con el acusado, no existe condiciones físicas que impidan el contacto entre ambos. 
Uno de los problemas más grande que enfrenta la legislación nicaragüense, es que a pesar de la aprobación de instrumentos jurídicos en materia de violencia de género, no existe unidad de criterio al valorar la prueba en materia de violencia de género, ya que muchos jueces se basan en la prueba tazada, considerando que si la víctima no comparece a declarar, los demás testimonios son insuficientes para dar por probados los hechos. En muchos casos no se valora que se trata de niñas o adolescentes ocultadas por las madres, con el fin de favorecer al acusado. Las desigualdades sociales se asienta sobre múltiples actos discriminatorios contra las mujeres, esto no es novedad, sin embargo uno de los principales problemas que se presenta en el sistema de justicia penal en Nicaragua es que aún persiste la falta de sensibilización del funcionario policial, fiscal y judicial para la aplicación del principio de igualdad real y no discriminación en todas las actuaciones donde intervienen, el desconocimiento que tienen en cuanto a la materia. Otro aspecto a valorar son las reprogramaciones de juicio, dándose un agotamiento de la víctima.

Con no ser suficiente lo anterior, muchas mujeres desconocen sus derechos, poseen nada 0 muy poca información de sus derechos, fuera y dentro del proceso penal. Esto es una debilidad en el sistema de justicia penal que debe ir mejorando. Así los funcionarios públicos a cargo de la investigación, ejercicio de la acción penal y administración de justicia, deben ir rompiendo barreras en el acceso a la justicia, siendo eficaces informadores y garantes de derechos que asisten a las mujeres víctimas de violencia.

En el proceso de administración de justicia los judiciales deben despojarse de estereotipos y prejuicios que obstaculizan el acceso a la justicia.

\section{De la diferencia a la desigualdad}

Al hablar de desigualdad debemos considerar el reconocimiento a la diferencia sexual, esto no tendría por qué ser motivo para incurrir en situaciones de coerción, subordinación y explotación entre mujeres y hombres, como generalmente sucede en nuestra sociedad actual. Es evidente que la diferencia femenina en las sociedades patriarcales se asienta sobre una óptica de dominación masculina históricamente construida. No obstante, cabe distinguir que la diferencia es un hecho. La igualdad es un derecho. De tal manera, que la desigualdad constituye una violación a la dignidad de la mujer como ser humano sujeta de derechos.

Astelarra (2004) afirma:

Una primera aproximación ideológica indica que cuando se habla de discriminación se intenta mediar las diferencias entre hombres y mujeres en términos de la distribución de bienes, servicios, prestigio y poder. En aquellas sociedades en las que hay desigualdades sistemáticas en su distribución se podría afirmar que existe desigualdad de género. Una sociedad igualitaria, en cambio, sería aquella en la que los roles sexuales son bastante similares, en términos de aquello que la propia sociedad valora positivamente (p. 8).

Sin duda, se produce un deslizamiento de la diferencia a la desigualdad sin querer, cuando se manifiestan relaciones desiguales de poder por razón del género.

\section{Igualdad de género en la ley}

Como resultado de las luchas feministas por el reconocimiento de derechos para las mujeres, se logró incluir en textos legales el principio de igualdad, según el cual todos somos iguales ante la ley, sin privilegio alguno bajo el principio esencial de la democracia. El principio de igualdad ante la ley es incompatible con sistemas legales de dominación o desigualdad, por razón del sexo. 


\section{Diferencia e igualdad}

Sabemos que no basta decretar la igualdad en la ley si en realidad no es un hecho. Para que así lo sea, la igualdad debe traducirse en oportunidades reales y efectivas para acceder a la justicia; gozar de autonomía; gozar de libertades para elegir pareja, tomar decisiones sin que por ello sea discriminada.

Sáez Carreras (1998) afirma:

La igualdad vista por la tradición de Igualdad de Derechos puede ser solamente conseguida si lo femenino-la diferencia-es altamente valorado. La tradición de la "Diferencia" considera la alteridad como deseable porque esta es crítica con las estructuras culturales. Lo que significa que estos otros seres humanos (las mujeres) sólo serán capaces de usar su influencia y toda su capacidad cuando éstas sean tratadas seriamente en igualdad (p. 328).

En este caso se hace necesario dar el valor a lo femenino, reconocer a la mujer en igualdad de condiciones para contraer derechos y obligaciones. Es pues, la plenitud femenina que permitirá su desarrollo en la sociedad. En el ámbito jurídico, esto se manifiesta en poder identificar cuándo la mujer es víctima de un delito de violencia de género, cuya principal causa radica en relaciones históricamente desiguales de poder y que influyen en el sometimiento de la mujer al hombre y que por tal razón muchas víctimas que denuncian se retractan de los hechos o niegan su existencia.

Conviene destacar la importancia de implementar un modelo jurídico que otorgue igual valoración jurídica a las diferencias, en un marco de garantías capaces de asegurar la efectividad de la aplicación de las normas. En contraste, la igualdad jurídica al no hacerse cargo de las diferencias y de su concreta relevancia en el ámbito de la equidad de género, está destinada a permanecer ampliamente inefectiva y a ser desmentida por las desigualdades concretas que se transforman en diferencias.

\section{Aparición del feminismo}

El feminismo defiende un cambio de paradigmas en las relaciones sociales que conduzca a la liberación de la mujer, eliminando desigualdades entre los sexos. El feminismo busca eliminar la opresión sexual y la discriminación, y alcanzar una condición de igualdad con el hombre.

Vollendorf (2005) dice:

Debido a la aparición del feminismo organizado durante el último tercio del siglo $\mathrm{xx}$, la mayoría de las discusiones sobre el tema se valen de una visión del feminismo como un movimiento que se enfoca en la lucha contra la desigualdad social (p. 2I).

El feminismo juega un papel preponderante en el reconocimiento de la igualdad establecida en textos constitucionales en diferentes países del mundo, ya que es producto del esfuerzo de una generación de mujeres que luchó primero por la aceptación del voto femenino, logrando expandirse a muchas más áreas proporcionando más libertades y el derecho de ciudadanía del que gozaban sus compañeros, preparando de esa manera el terreno para que se desarrollara una igualdad formal que sigue teniendo repercusiones hasta nuestros días, persistiendo todavía la lucha por el reconocimiento del potencial e igualdad real femeninos.

Wallach (2008) sobre la historia del feminismo, afirma:

Durante la última década, el llamado de Virginia Woolf en favor de una historia de las mujeres- que había escrito más de 50 años antes- ya ha obtenido una respuesta. Inspirándose directa o indirectamente en la agenda política del movimiento de mujeres, 
los historiadores sólo documentaron las vidas de mujeres de mediana edad en varios periodos históricos, sino que también trazaron cambios en las posiciones económicas, educativas y políticas de las mujeres de varias clases sociales en la ciudad, en el campo y en las naciones -estado (p.33).

De tal manera que el feminismo da lugar a movimientos feministas de carácter político, cultural y económico que tienen como objetivo la igualdad de derechos entre hombres y mujeres.

La discusión sobre la posición de la mujer en cuanto a cuestiones relacionadas con la política, la libertad y la esclavitud, nunca respetaron las fronteras nacionales de cada país en el que se originaban estas discusiones. La vida política, social y económica de la mujer está moldeada por conceptos culturales y era una prioridad obtener la igualdad. Lucha que persiste hasta nuestros días.

Silva Charvet(2005) afirma sobre la identidad femenina que esta:

...ha sido un tema central en el debate feminista. Su deconstrucción y construcción discursiva ha comprometido un penetrante ejercicio de crítica a los diferentes sistemas de poder y dominación pasados y presentes, así como la formulación de nuevas proposiciones teóricas "desde las mujeres" en torno al poder, la política y la cultura" (p.II).

La identidad femenina que caracterizan a la mujer en su condición de mujer, juega un papel preponderante en el debate feminista, porque busca posicionar a la mujer en condiciones de igualdad. Además, las nuevas proposiciones teóricas en las que la mujer tenga participación directa, requieren considerar las circunstancias históricas y sociales.

Sau Sánchez (2000) sobre ¿Qué es feminismo? Refiere:

El caso es que el feminismo existe, en tanto que acción organizada de las mujeres en defensa de sus intereses, de forma ya incuestionable desde finales del siglo XVIII, coincidiendo en el tiempo de la publicación por parte de Olympia de Gouges de "Los derechos de la mujer y de la ciudadana"( 1791) como réplica a la Declaración de Derechos del Hombre (1792), que no incluía a las mujeres, todo ello en el marco de la Revolución Francesa, y el libro de la autora inglesa Mary Wollstonecraft Vindicación de los derechos de la mujer (I 792), primero en su género. En 1794 la condesa romana Rosa California publica Breve defensa de los derechos de la mujer, mientras los primero periódicos femeninos en Italia reclaman derechos de igualdad para las mujeres. En 1848 se produce en Estados Unidos la Declaración de Séneca Falls, redactada por Lucrecia Mott y Elisabeth Cady Stanton, rectificando al estilo de como lo había hecho Olympia de Gouges con la Declaración de los Derechos del Hombre y el Ciudadano, la Declaración de Independencia de Estados Unidos tampoco las incluía (p. I89).

Las ideas expuestas, coinciden en que el feminismo tiene un fin común: el reconocimiento de los derechos de la mujer a ser tratada en condiciones de igualdad.

\section{Juicio de razonabilidad}

El juicio de razonabilidad jurídica pretende la aplicación adecuada de la norma jurídica, evitando arbitrariedades y actuando de acuerdo al principio de proporcionalidad de la ley.

Martínez \& Zúñiga (20II) afirman:

El control de constitucionalidad implica necesariamente un juicio de razonabilidad, al punto que, como apunta Haro, esta última "ha venido a constituirse en un sinónimo de constitucionalidad, pues como dice Germán Bidart Campos, lo razonable es lo ajustado a la 
Constitución, no tanto a la letra como a su espíritu, y lo irrazonable es lo que conculca la Constitución, lo inconstitucional" (p. 22).

En este sentido debe aplicarse la ley considerando los límites del derecho, según el contexto histórico y socio-jurídico de la legislación.

En materia de equidad de género tiene relevancia el juicio de razonabilidad en virtud que debe considerarse que los derechos tienen contenido y alcance, y deben estar recogidos en el marco constitucional. Además, la aplicación de la norma constitucional debe ser fundamentada, aplicándose la igualdad con proporcionalidad y de acuerdo a la equidad de género. En nuestra legislación el Decreto 42-2014 está en correspondencia con la norma constitucional cuando de aplicar una igualdad real se trata, sin embargo la disonancia se pone de manifiesto cuando el judicial injustamente aplica tal principio. Tal es el caso cuando el judicial no brinda un trato desigual en aquellos casos que por sus específicas condiciones así lo requieran. Por ejemplo, algunos jueces exigen la declaración de una niña víctima de violencia sexual para poder decidir sobre la responsabilidad del autor, cuando es sabido que la niña víctima no puede ser obligada a comparecer ante un tribunal, ni ser sometida a victimización secundaria. Entonces, la potestad normativa contenida en la ley y el fin perseguido se ven anuladas por la falta de un correcto control constitucional de la norma.

\section{Igualdad formal para igualdad real}

I. La igualdad entre hombres y mujeres

La igualdad de género es un principio constitucional que establece que mujeres y hombres son iguales ante la ley, lo que implica la igualdad de las personas sin distinción alguna, pues tanto mujeres y hombres tienen los mismo derechos y deberes frente a un Estado de Derecho y la sociedad en su conjunto.

Hemos afirmando que no basta con decretar la igualdad en la ley (igualdad formal), sino que debe traducirse en oportunidades reales y efectivas (igualdad material) para acceder sin discriminación alguna al sistema de justicia, gozar de libertades y autonomía en todos los ámbitos de su vida, sin que sea vista como un objeto.

El reconocimiento de la igualdad de género como conquista histórica de las mujeres, debe ser un derecho en el que la mujer ya no sea vista como inferior al hombre, en el derecho de tomar decisiones sobre su vida, su cuerpo y su familia, sin injerencias o actos de violencia de ningún tipo.

A partir del reconocimiento de la igualdad en el texto constitucional nicaragüense, corresponde avanzar hacia la igualdad de género y el cumplimiento del rol del Estado dentro de sus políticas públicas, para alcanzar la igualdad de género. La Corte Suprema de Justicia ha dado pasos en ese sentido a través de la creación del observatorio en materia de género.

El mandato de igualdad en la ley distingue entre el principio de igualdad formal o igualdad ante la ley, como mandato de trato jurídico a hombres y mujeres que están en la misma situación, e igualdad material, como una reinterpretación de aquélla en el Estado social de Derecho, que teniendo en cuenta la posición jurídica real en que se encuentra la mujer con relación al hombre acusado de cometer un delito de violencia de género, exige una equiparación real, estructural y efectiva en el proceso penal.

Para alcanzar la igualdad material, los jueces deben aplicar la ley, aplicar normas aparentemente desiguales a la igualdad formal, con el objetivo de lograr una equidad de género y una igualdad real, considerando que la violencia se manifiesta en la relaciones desiguales de poder. En el caso de los niños, niñas y adolescentes víctimas de violencia sexual, se les debe valorar la condición de vulnerabilidad, asimetría de edad, relaciones de autoridad y poder en que pueden encontrarse 
al momento de ser víctimas de un delito y considerar las condiciones que les impiden comparecer a un juicio.

Esto es, platearse la igualdad de derecho y la igualdad de hecho como derecho subjetivos fundamentales ante los tribunales.

Para poder aplicar la igualdad real como un derecho fundamental es necesario concebir la igualdad de hecho como fundamental, reconociendo el derecho subjetivo fundamental de recibir un trato jurídico desigual y favorable para conseguir la igualdad real, en condiciones reales de la existencia.

Atienza (2005) afirma:

Un segundo campo en que se efectúan argumentos jurídicos es el de la aplicación de normas jurídicas a la resolución de casos, bien sea esta una actividad que llevan a cabo jueces en sentido estricto, órganos administrativos en el más amplio sentido de la expresión o simples particulares. Aquí, a su vez, cabría distinguir entre argumentaciones en relación con problemas concernientes a los hechos, o bien al derecho (estos últimos en sentido amplio, podrían llamarse problemas de interpretación). Puede decirse que la teoría de la argumentación jurídica dominante se centra en las cuestiones - los casos difíciles - relativas a la interpretación del derecho y que se plantean en los órganos superiores de la administración de justicia. Ahora bien, la mayor parte de los problemas sobre los que tienen que conocer y decidir tanto los tribunales como los órganos no jurisdiccionales de la Administración... La dogmática es, desde luego, una actividad compleja en la que cabe distinguir esencialmente estas tres funciones: I) suministrar criterios para la producción del derecho en las diversas instancias en que ello tiene lugar; 2 ) suministrar criterios para la aplicación del derecho; 3) ordenar y sistematizar un sector del ordenamiento jurídico (p. 3).

De acuerdo a Atienza, el juez debe dar las argumentaciones jurídicas en el momento de aplicar el derecho. Esto es, en materia de equidad de género dar los criterios jurídicos para aplicar el principio de igualdad, brindar en sus resoluciones las argumentaciones necesarias que motiven sus resoluciones y en este contexto los jueces tienen la responsabilidad de argumentar la aplicación del principio de igualdad, así como las justificaciones del porqué considerar en algún momento un criterio de desigualdad principalmente cuando se trata de niños, niñas y adolescentes. Es pertinente valorar que muchas resoluciones judiciales carecen de argumentaciones jurídicas que justifiquen la aplicación del derecho, máxime cuando se trata de violencia de género, porque requiere aplicar principios fundamentales a fin de no vulnerar el derecho a la igualdad, no discriminación y aplicar una igualdad real o estructural.

\section{La fórmula de igualdad. Igualdad como concepto valorativo}

El principio de igualdad da el fundamento para justificar un tratamiento desigual, es decir, para permitirse el juzgador un tratamiento desigual bajo el principio de igualdad real.

Hemos venido planteando que la Constitución Política registra el principio de igualdad de carácter normativo. La igualdad en el contenido de la ley constituye un mandato del legislador, aunque las prescripciones de derecho indican que deben tratar de la misma manera a los iguales y de diversa manera a los desiguales, en la ley nos encontramos con una clásica noción de igualdad dirigida hacia el judicial, en virtud que este es quien ejerce jurisdicción y entonces debe tratar de la misma forma; o sea igual, tanto al acusado como a la víctima en el proceso. No obstante, sabemos que la víctima y el acusado se encuentran en condiciones desiguales, pues la víctima de violencia psicológica tiene un menoscabo psicológico que no la puede poner en la misma condición que el hombre. Por ejemplo, una niña víctima de violencia sexual, sometida por años a agresiones sexuales no podría en ningún momento estar en condiciones de igualdad con el acusado, cuando la madre encubre los abusos sexuales de su hija, la oculta para que no comparezca al proceso y no pueda declarar y manifestar toda la violencia sexual que por años ha vivido. Es justo en circunstancias como estas que el juzgador haga un trato desigual, es aquí 
donde se debe tratar de diversa manera a lo desigual e implementar una igualdad material y es precisamente de lo que carecen las resoluciones de nuestros jueces y tribunales especializados en materia de violencia de género, ya que no presentan en sus resoluciones los argumentos que indiquen en qué momento del proceso o del juicio realizaron juicios de valor en el principio de igualdad, cuando los elementos (víctima y acusado) fueron sometidos a un análisis de comparación para determinar si son iguales o desiguales, para entonces aplicar un derecho a la igualdad justo, equitativo y real.

Muchos consideran que la igualdad en el proceso penal de las partes está relacionada a las alegaciones, intervenciones en el proceso, sin embargo este no es el contexto de la igualdad en el proceso.

Díaz García (2012) al respecto afirma:

En este sentido parece manifestarse Pfeffer cuando sostiene que la igualdad en la aplicación de la ley supone "un trato igualitario a todas las personas comprometidas o sometidas a un mismo proceso o juicio". En la misma línea parece incluirse Evans Espiñeiro, quien sostiene que esta igualdad "contempla la custodia de importantes bienes jurídicos como son la igualdad de las partes en la relación jurídica procesal". Desde la perspectiva que se está presentando, las partes de un mismo proceso serían lo igual (o iguales) y, por lo mismo, tendrían derecho a ser tratadas de la misma manera al interior de un mismo proceso. No resulta posible coincidir con esta forma de entender lo igual en el ámbito de la igualdad en la aplicación de la ley. Las partes de un mismo proceso no son iguales entre sí frente al juzgador. Más bien, al contrario, son desiguales para el tribunal. Sólo si se admite que son desiguales resulta posible comprender por qué son tratados de diversa manera ...Ahora bien, aunque las partes de un mismo proceso no son iguales entre sí, se les deben otorgar las mismas posibilidades en lo relativo a alegar, probar y controvertir las pretensiones de la contraria. Sin embargo, y como es evidente, ser iguales y contar con iguales posibilidades procesales no significan lo mismo. Seguramente una confusión entre esas dos ideas es lo que produce la errónea comprensión de lo igual en la igualdad en la aplicación de la ley. Desechada esta opción, es necesario buscar otra forma de explicar el significado de lo igual y lo desigual en esta materia (p. 36).

En este sentido vemos que la igualdad no se trata del número de intervenciones de las partes por igual el proceso, sino de las circunstancias que se encuentra cada una de las partes en el proceso y reiteramos, la mujer víctima de violencia no se encuentra en las mismas condiciones que el acusado ante el juez. En términos de igualdad, vemos que los jueces y tribunales perciben la igualdad en un sentido contrario, algo que constituye una debilidad en el sistema de justicia penal, por los impartidores de justicia. Por lo tanto, los jueces no deben buscar identidad en los casos, sino que coincidan en su propiedades lo que equivale a igualdad.

Tratar de la misma manera implica dar el mismo tratamiento a las partes, frente a iguales condiciones y cuyas consecuencias jurídicas serán iguales, dando a cada quien lo que le corresponde. El judicial utiliza las mismas disposiciones legales para interpretarlas de la misma manera y adopta la misma decisión en casos iguales.

Ahora bien, tratar de manera diferente en el ámbito de la igualdad de la ley, significa que los jueces deben utilizar diferentes disposiciones para casos desiguales y argumentar porque se da un trato diverso a las partes en el proceso.

Consecuentemente, los casos desiguales deben ser tratados de diversa manera, tal es el caso de las mujeres víctimas de violencia sexual, psicológica, física, patrimonial en relación al hombre acusado. En estados de causa considerados como desiguales se pretende la misma consecuencia jurídica de acuerdo a los hechos descritos en la ley. 


\section{Prohibición de discriminación en la Constitución Política de Nicaragua}

I. El principio de igualdad como principio inspirador del ordenamiento jurídico nicaragüense

La conciliación del principio de igualdad formal, la prohibición de cualquier tipo de discriminación debe determinar la actuación diferenciadora del legislador y del juzgador.

La igualdad es un principio básico del ordenamiento jurídico nicaragüense, tal es la manifestación de la igualdad en la aplicación de la ley, dirigida a los jueces y tribunales que imparten justicia. La igualdad en la aplicación de la ley, además, es un derecho fundamental en el ordenamiento jurídico nicaragüense. En el ámbito de género merece especial atención la Ley $\mathrm{N}^{\circ} 779$, en la que ya se introducen medidas de acción positivas en favor de las mujeres. Es importante hacer hincapié que igualdad, libertad y dignidad son inherentes a la hora de valorar la condición de igualdad de hombres y mujeres, ya que las mujeres en un sistema patriarcal y de condiciones socio cultural desfavorable para ellas afecta no sólo su condición desigual con respecto al hombre, sino su dignidad y libertad.

Según el arto. $36 \mathrm{Cn}$ :

Toda persona tiene derecho a que se respete su integridad física, psíquica y moral. Nadie será sometido a torturas, tratos crueles, inhumanos o degradantes.

El arto. 4 constitucional establece: “...el respeto a la dignidad humana...”

El derecho a la igualdad no tiene autonomía propia, ya que integra todos y cada uno de los derechos fundamentales, lo cuales deben tener validez y aplicación en todo el ordenamiento jurídico.

\section{Principio de igualdad en las convenciones internacionales}

Becerra \& Rolander (2006) afirman:

Desde el nacimiento de la Organización de las Naciones Unidas y de la emisión de la Declaración Universal de los Derechos Humanos (1984) se inició formalmente un movimiento internacional para proteger y garantizar la vigencia plena de los derechos fundamentales para todas las personas sin distinción de raza, sexo, origen étnico, edad - nacionalidad. Desde la perspectiva de los derechos básicos, el derecho a la no discriminación ha sido parte sustancial del circuito de protección internacional. Sin embargo, a pesar de existir una infraestructura institucional, jurídica y normativa internacional para la protección de los derechos fundamentales, esta protección no se ve reflejada en el ámbito nacional en la mayoría de las naciones en virtud de la ausencia de mecanismos institucionales actualizados y de una cultura del respecto a la diversidad que den concreción al espíritu de las normas internacionales (p. 78).

Hasta la aprobación de la Carta de las Naciones Unidas (ONU) en 1945 y la Declaración de los Derechos Humanos de 1948, la lucha por la no discriminación era invisible. Su finalidad era fomentar el respeto por los derechos humanos y las libertades fundamentales. Es a partir de estos instrumentos internacionales que se empieza a hablar de derechos humanos sin discriminación alguna, iniciándose una lucha histórica de las mujeres por obtener una condición de igualdad y su inclusión en las leyes y textos jurídicos. Como consecuencia se han aprobado y ratificado los siguientee instrumentos jurídicos internacionales.

I) La Declaración Americana de los Derechos y Deberes del hombre. Aprobada y ratificada en 1948 mediante la cual se declara que todos los hombres nacen libres e iguales en dignidad y derechos y dotados como están por naturaleza de razón y consciencia, deben conducirse fraternalmente los unos con los otros. 
Fue aprobada en la IX Conferencia Internacional Americana realizada en Bogotá en 1948, en la que se dispuso la creación de la Organización de los Estados Americanos (OEA), este fue el primer acuerdo internacional sobre derechos humanos. Luego, seis meses después se aprobó la Declaración Universal de los Derechos Humanos, que muchos países incorporaron en sus constituciones.

El cumplimiento del deber de cada uno, es una exigencia del derecho de todos. Derechos y Deberes se integran correlativamente en toda actividad social y política del hombre. Si los derechos exaltan la libertad individual, los deberes expresan la dignidad de esa libertad.

Nótese que este logro siendo uno de los más importantes en materia de igualdad ante la ley, no incluye a la mujer en su identidad femenina, en su género, es decir aún no se había reconocido a la mujer como sujeto de derechos humanos.

2) Declaración Universal de Derechos Humanos, adoptada y proclamada el 10 de diciembre de 1948; Nicaragua como miembro de las Naciones Unidas ha reafirmado en la Carta su fe en los derechos fundamentales del hombre, en la dignidad y el valor de las persona humana y en la igualdad de derechos hombres y mujeres, y se ha declarado resuelto a promover el progreso social y a elevar el nivel de vida dentro de un concepto más amplio de la libertad. Esta declaración contiene numerosos derechos humanos a garantizar y proteger en el desarrollo social de nuestro país.

La Declaración Universal de los Derechos Humanos es un documento que forma parte de la historia de los derechos humanos, en la cual participaron los representantes de todas las regiones del mundo, proclamada por la Asamblea General de las Naciones en París, el 10 de Enero 1984 en su Resolución 217 A (III), la cual también establece por primera vez, los derechos humanos fundamentales que deben protegerse en el mundo entero.

La Declaración Universal de Derechos Humanos en su arto.I establece:

"Todos los seres humanos nacen libres e iguales en dignidad y derechos y, dotados como están de razón y conciencia, deben comportarse fraternalmente los unos con los otros"

3) Del pacto internacional de Derechos, Civiles y Políticos, suscrito por Nicaragua en el año 1990; constituye un tratado jurídicamente vinculante para Nicaragua, que comprende el derecho a la vida, a la intimidad, a un proceso justo, a la libertad de expresión, a la libertad religiosa, a no ser sometido a la tortura y a la igualdad ante la ley.

Es un tratado multilateral general que reconoce Derechos civiles y políticos y establece mecanismo para su protección y garantía. Fue adoptado el 16 de diciembre de 1966 por la Asamblea General de las Naciones Unidas mediante Resolución 2200 A (XXI) y entró en vigor el 23 de marzo de 1976.

Conviene destacar que al mismo tiempo que se adoptó el Pacto Internacional de Derechos Económicos, Sociales y Culturales también se adoptó la Declaración Universal de los Derechos Humanos, llamada Carta Internacional de Derechos Humanos.

Nos permitimos poner de relieve que este instrumento promueve la igualdad en los derechos del hombre y del ciudadano basado, al igual que en el modelo precedente, sobre la asunción del sujeto masculino como parámetro. Se resuelve en la asimilación jurídica de las mujeres a los varones $y$, por consiguiente, en una ficción de igualdad que deja de hecho sobrevivir a la desigualdad como producto del desconocimiento de la diferencia. La igualdad del primer tipo es una igualdad amputada también en el plano jurídico, relativa sólo a una parte privilegiada de seres humanos arbitrariamente confundidos con la totalidad. 
4) Declaración sobre los principios fundamentales de justicia para las víctimas de delitos y abusos de poder, suscrita en Nicaragua el 29 de noviembre de 1985; establece mecanismo de justicia para las víctimas de delitos de cualquier tipo de violencia $\circ$ discriminación en todas sus formas y sobre formas de eliminación mediante políticas institucionales de cualquier forma de manifestación de abuso de poder, tanto de las instituciones públicas como privadas. Fue adoptada por la Asamblea General en su resolución 40/34, de 29 de noviembre de 1985.

Esta Declaración fue en atención al Sexto Congreso de las Naciones Unidas sobre Prevención del Delito y Tratamiento del Delincuente, donde se recomendó que las Naciones Unidas continuaran su actual labor de elaboración de directrices y normas acerca del abuso de poder económico y político.

El arto. 3 de la Declaración sobre los Principios fundamentales de justicia para las víctimas de delitos y del abuso de poder, reza:

Las disposiciones de la presente Declaración serán aplicables a todas las personas sin distinción alguna, ya sea de raza, color, sexo, edad, idioma, religión, nacionalidad, opinión política o de otra índole, creencias o prácticas culturales, situación económica, nacimiento o situación familiar, origen étnico o social, o impedimento físico.

Esta Convención está enfocada en el tratamiento de las víctimas de abuso de poder, pero también recoge la no discriminación, en un instrumento jurídico valioso, cuyo contenido regula el tratamiento a seguir en las víctimas de abuso de poder y de delitos.

5) Declaración sobre la Eliminación de la Violencia contra la mujer. Esta convención adoptada por Nicaragua, en el mes de diciembre del año 198I ante las Naciones Unidas, recomienda la adopción de medidas pertinentes de cara a la erradicación y eliminación de violencia contra la mujer. Estableciéndose medidas concretas para proteger a las mujeres contra la violencia, para llevar a la práctica la igualdad entre hombres y mujeres.

6) Convención Interamericana para Prevenir, Sancionar y Erradicar la Violencia contra la Mujer "Convención Belén do Pará". Consiste en la Convención Interamericana para prevenir, sancionar y erradicar la violencia intrafamiliar contra la mujer, la cual fue ratificada por Nicaragua el día 9 de junio de 1994.

Esta Convención obliga a los Estados Partes a penalizar de forma progresiva los delitos que atentan contra la integridad física, psíquica y moral de la mujer causada por el grado de parentesco o afinidad derivado de las relaciones desiguales de poder.

7) Convención sobre los Derechos del Niño y la Niña, aprobada el 2 de septiembre de 1990. Establece el reconocimiento a los derechos del niño y niña, donde el interés de los niños sea de consideración primordial, reconociendo la importancia de la vida familiar para los niños. Dentro del marco de protección se encuentra la eliminación de la venta de niños, la prostitución y pornografía infantil, entre otras.

8) El Código Penal de Nicaragua, cuya vigencia inicia a partir del nueve de julio del 2008. Incorporando nuevos delitos como la manipulación genética, violencia domestica e intrafamiliar, utilización de niños, niñas, adolescentes o discapacitados o personas de la tercera edad para mendicidad, el contagio provocado, entre otros, así como los delitos de inseminación sin consentimiento y la inseminación fraudulenta.

El arto. $5 \mathrm{CP}$ introduce el reconocimiento y protección a la víctima, obligando al Estado a tratar a las víctimas con el debido respeto a la dignidad inherente al ser humano. 
Las medidas de protección de urgencia contenidas en el Código Penal quedaron taxativamente enumeradas con el objetivo de garantizar la integridad y la debida protección a las víctimas de violencia intrafamiliar.

Becerra \& Rolander (2006) afirman:

La defensa de los derechos humanos tienen una visión y un propósito: velar por la libertad, el bienestar, la igualdad y la dignidad de todos los seres humanos. Uno de los logros más notables del siglo $X X$ fue el desarrollo del reconocimiento de estos derechos. Sin duda, el principio de igualdad de derechos ha sido la fuerza impulsora de los derechos humanos y constituye uno de los pilares del desarrollo de la humanidad que destaca la igualdad de oportunidades y la convivencia en la diversidad. El carácter universidad de los derechos fundamentales exige que todas las personas se traten de igual modo, sin discriminación, pues para algunos estudiosos del tema el derecho a la no discriminación se vuelve el derecho más fundamental de todos (p. 79).

Es importante subrayar que además de la gama de instrumentos jurídicos a favor de la igualdad y no discriminación, también nos encontramos con:

I) Primer encuentro de magistradas de las Cortes Supremas de Justicia y Cortes constitucionales de América Latina y El Caribe: "Por una Justicia de Género". Fue organizado por la Corte Suprema de Justicia de Costa Rica y el Programa Mujer, Justicia y Género del Instituto Latinoamericano de Naciones Unidas para la Prevención del Delito y Tratamiento del Delincuente (ILANUD) y tuvo lugar 4, 5 y 6 de diciembre del 2000. Tuvo como fin la promoción efectiva de la Convención sobre la Eliminación de todas las Formas de Discriminación contra la Mujer y Erradicar la violencia contra la mujer como marco jurídico, entre otros.

2) Cumbre Judicial de Cancún. En la ciudad de Cancún, México, los días 27 al 29 de noviembre del 2002, en la VII Cumbre lberoamericana, las y los Presidentes de Cortes Supremas y Tribunales Supremos de Justicia, acordaron "Declaración Principal de la VII Cumbre Iberoamericana de Presidentes de Cortes Supremas y Tribunales Supremos de Justicia noción de Acceso a la Justicia” (Declaración de Cancún 2002). Siendo el tema principal el acceso a la justicia de forma pronta, completa e imparcial.

3) Reglas de Brasilia sobre el Acceso a la Justicia de las personas en condición de vulnerabilidad, pobreza y acceso a la Justicia. Nacen en la Cumbre Judicial Iberoamericana en 2008, y tienen como preocupación central, el acceso a la justicia de las personas que se encuentran en condición de vulnerabilidad, desde la exigencia de que los sistemas judiciales sean reales instrumentos de defensa de los derechos de las personas, sobre todo de las más vulnerables.

4) Declaración y Programa de Acción de AMMAN. Dentro del marco normativo internacional, uno de los instrumentos recientes con mayor relevancia es la Declaración y Programa de Acción de Amman entre el 5 y 7 de noviembre del 2012 en Jordania, acordada la Onceava Conferencia Internacional del Comité Internacional de Coordinación de las Instituciones Nacionales para la Promoción y Protección de los Derechos Humanos.

Sin bien es cierto que el movimiento internacional de los derechos fundamentales ha impulsado el derecho a la no discriminación y que ha codificado una gama de instrumentos jurídicos en la materia, también resulta una realidad que existen grandes obstáculos para la protección internacional y nacional real de los derechos fundamentales (Becerra \& Rolander, 2006, p. 85) 
Lo anterior sugiere que los Estados deben tutelar el derecho a la no discriminación y en consecuencia prohibir toda forma de discriminación, fortalecer medidas y dar seguimiento a fin de erradicar políticas excluyentes.

\section{El principio de igualdad material como finalidad del trato desigual}

El principio de igualdad formal o igualdad ante la Ley implica que la norma es la misma para todos y que se aplicará a todos por igual, garantizando la igualdad en aptitudes a todos por igual, el goce de los derechos y libertades, pero no asegura que el contenido de esa ley sea igualitaria.

La evolución del principio de igualdad parte, por tanto, de la aceptación de la desigualdad originaria de los individuos y establece la facultad e, incluso, la obligación para que los poderes públicos garanticen una auténtica igualdad material, o sea, para procurar la igualdad real y efectiva. De esta forma se difuminan los rasgos característicos de la Ley (universalidad, generalidad y abstracción) para permitir la aprobación de leyes que sí permitan una diferencia de trato que establezcan consecuencias jurídicas diferentes para situaciones distintas. En este contexto, el reconocimiento de leyes singulares 0 diferenciadoras permite que se dé un trato diferenciado para supuestos diferentes, dentro de unos límites muy concretos: la diferenciación nunca podrá ser arbitraria 0 discriminatoria, sino que deberá ser motivada y razonable. En el constitucionalismo actual el valor igualdad se concibe en ese doble ámbito, que hace coexistir la igualdad formal y la igualdad real, que se limitan y se complementan mutuamente (Sala et al., p. $39,2008)$.

El principio de igualdad no es absoluto, ni excluye la posibilidad de ejercer un trato desigual ante supuestos de hechos que en sí mismo son desiguales, a partir de una valoración del ámbito propio de actuación. En este sentido el juicio de la razón práctica para valorar la viabilidad de la diferenciación nos lleva a uno de los aspectos más complejos que plantea la cláusula de igualdad y que corresponde a los jueces justificar.

Las comparaciones de situaciones de hecho son un criterio fundamental para discernir sobre la existencia de situaciones discriminatorias o, simplemente, de trato desigual.

El trato diferencial o de discriminación es la justificación precisamente del criterio diferenciador en orden a la consecución de una finalidad determinada, en este caso la igualdad entre mujeres $y$ hombres en el proceso penal.

\section{Políticas de Estado}

Nicaragua como parte de su inclusión de la no discriminación por razón de sexo, con el fin de erradicar la violencia en todas sus manifestaciones, se desarrolla en el Decreto $\mathrm{N}^{\circ}$ 43-20I4 del treinta y uno de Julio del 2014 "Política de Estado para el Fortalecimiento de la Familia Nicaragüense y Prevención de la Violencia" conformada por objetivos estratégicos, estrategias generales y líneas de acción que deben ser aplicados en materia de violencia de género.

Uno de los objetivos estratégicos:

3. Crear o adecuar, normas de actuación, instrumentos y servicios que mejoren el acceso y oportunidades a mujeres, niños, niñas y adolescentes en materia de prevención, atención y protección de los Derechos Humanos y de igualdad real, a través de una intervención integral, ágil, eficiente, oportuna y coordinada de las instituciones del Estado de Nicaragua que trabajan la prevención y atención de la violencia. 
Hay un punto relevante a valorar y es que esta política de Estado, pese a ser reciente, incluye directamente la posibilidad de aplicar una igualdad real en materia de violencia de género. Pero en la realidad del proceso, ni siquiera se toma en cuenta y no se dan los argumentos que justifiquen su aplicación.

También recoge el Modelo de Atención Integral para elevar la cantidad de atención a la violencia de género haciendo uso de instrumentos que garanticen la prevención y la atención integral basada en el respeto a los derechos humanos con una perspectiva de género, que sea de alta calidad humana y técnica, ágil, eficiente, oportuna e integral.

En el mismo contexto se requiere estudios interdisciplinares que permitan conocer las diversas expresiones de violencia hacia la mujer, los factores que la originan, reproducen y evolucionan, frecuencia y ubicación del problema, consecuencia en el ámbito individual, familiar y social. Todo con el fin de evitar cualquier forma de discriminación y violencia contra la mujer, aplicando la Ley $\mathrm{N}^{\circ}$ 779. Falta entonces aplicar adecuadamente esta política de Estado en las resoluciones judiciales a fin de justificar la desigualdad entre hombres y mujeres vigente aun en nuestros días.

Este plan del gobierno nicaragüense es fruto de proceso de reflexión y debate interno acerca de las necesidades que existen en Nicaragua, para avanzar y garantizar la igualdad efectiva entre hombres y mujeres, y en el que se ven implicados tanto las estructuras, unidades y servicios de justicia, producto también de las Convenciones en materia de violencia de género reconocidos en el arto. $46 \mathrm{Cn}$ y recogidos en el arto. 5 de la Ley $\mathrm{N}^{\circ} 779$.

El marco jurídico-normativo nacional en materia de igualdad, además del Código Penal y el Código de la Niñez y la Adolescencia tenemos:

I) Constitución Política de Nicaragua de 1987 y sus reformas del 2014. Establece que todas las personas son iguales ante la ley y tienen derecho a igual protección y no habrá discriminación alguna por motivo de nacimiento, nacionalidad, credo político, raza, sexo, idioma, religión, opinión, origen posición económica o condición social (Art 27) y en el arto. 48 establece la igualdad sustantiva $\circ$ igualdad real al considerar que se deben eliminar los obstáculos que impidan esa igualdad entre hombre y mujeres.

2) Ley de Igualdad de derechos y Oportunidades. La Ley 648 (2008) incorpora recomendaciones en el Programa de Acción suscrito en Viena (1993), en el marco de la Conferencia Mundial de Beijing (1995) y las concernientes a los derechos humanos de las niñas y los niños. Establece la creación de una estructura de género y la existencia, de forma que se garantice el ejercicio efectivo de la igualdad real entre hombres y mujeres en todas las instituciones del Estado.

3) Ley integral contra la violencia hacia la mujer. La Ley $\mathrm{N}^{\circ} 779$ entró en vigencia el 22 de junio del año 2012 y tiene por objeto actuar contra la violencia que se ejerce hacia las mujeres, con el propósito de proteger los derechos humanos de las mujeres y garantizarle una vida libre de violencia, que favorezca su desarrollo y bienestar conforme a los principios de igualdad y no discriminación; establece medidas de protección integral para prevenir, sancionar y erradicar la violencia, impulsando cambios en los patrones socio culturales y patriarcales que sostienen las relaciones de poder.

4) Código de Familia. La Ley $\mathrm{N}^{\circ} 870$ (20l4), regula todo lo concerniente al tema de familia, tanto en la parte sustantiva como procedimental. Considera la normativa relacionada con la familia y sus integrantes, como un derecho autónomo. Sus principios están basados en la igualdad de derechos, deberes y oportunidades en las relaciones del hombre y la mujer, mediante la coparticipación en las responsabilidades familiares. 
5) Ley contra la trata de personas, Ley $\mathrm{N}^{\circ} 896$, publicada el 25 de febrero del 2015. Los fines que se pretenden lograr con la aprobación de esta ley son el prevenir y combatir la trata de personas en todas sus formas y manifestaciones, prestando especial atención a las víctimas mujeres, niñas, niños y adolescentes.

6) Plan Nacional de Desarrollo Humano (PNDH 20I2-20।6). Establece como premisa "Las mujeres como sujetos de cambios sociales y del desarrollo, el acceso a los bienes y medios productivos, equidad en la participación e igualdad derechos y oportunidades,...".

Son varios los instrumentos nacionales e internacionales en materia de género. Tienen en común la búsqueda de la igualdad y el reconocimiento de los derechos de la mujer como sujeto de derechos humanos. No obstante, en la práctica, vemos deficiencia en la aplicación del principio de igualdad. Esto se debe a la falta de sensibilización en los funcionarios a cargo de investigar, acusar y juzgar delitos relacionados con la violencia de género. El gobierno de Nicaragua ha capacitado a sus funcionarios en esta materia, sin embargo los resultados no son siempre satisfactorios, debido a los prejuicios de los que aún están revestidos nuestros jueces, fiscales y policías.

2. ¿Se ha conseguido la igualdad real de derechos entre mujeres y hombres, una vez reconocida la igualdad legal?

El camino hacia la igualdad entre los sexos no sólo ha significado una ardua lucha por desterrar el entendimiento de la igualdad como semejanza, sino también por lograr que cada Estado cumpla con sus obligaciones legales en cuanto a garantizarla. El Estado no cumple con la obligación otorgando los mismos derechos a las mujeres que ya gozan los hombres, sino que para ello se requiere que el Estado se involucre activamente en la eliminación de todas las formas de discriminación contra las mujeres en cualquier plano y ámbito. En nuestro caso de estudio en el proceso, vemos que a través de las políticas de Estado, este asume tal responsabilidad, derivada del texto constitucional que prohíbe cualquier tipo de discriminación, siendo exigible el respeto, protección y garantía del principio de igualdad entre mujeres y hombres.

Esto nos lleva a analizar si actualmente se ha reconocido el principio de igualdad real, sin embargo existen obstáculos que impiden su cumplimiento porque no hay una realización progresiva del mismo, ni supervisión de su cumplimiento.

La pobreza de la mujer, el desempleo, pocas oportunidades en los ámbitos de la vida de la mujer que impiden su autonomía influyen negativamente en la violencia, ya que propicia un patriarcado de consentimiento por dependencia económica y muchas veces por dependencia emocional, y como consecuencia son víctimas de violencia de hombres agresores que colocan a la mujer en un nivel de inferioridad y sumisión, provocándose impunidad en los procesos penales.

Como se ha dicho, se ha avanzado mucho en la legislación de Nicaragua en materia de género, sin embargo con el reconocimiento constitucional, suscripción a Convenciones e instrumentos jurídicos internacionales, la igualdad real aún no ha sido posible a plenitud debido a la ineficacia en la aplicación de tales instrumentos.

\section{Espejismo de la igualdad.}

El derecho de igualdad se convierte en un efecto reflejo en la medida que al ser reconocido por el legislador en el texto constitucional y no dar lugar a situaciones de protección jurídica en condiciones tanto de igualdad como de desigualdad.

JELLINEK (2000) apunta: 
La "igualdad en todas sus formas nunca puede llegar a tener como contenido una pretensión individual. Es derecho objetivo y su eficacia en la esfera jurídica individual es un mero efecto reflejo" (3). De esta forma, el gran autor alemán venía a integrar a la igualdad dentro del grupo de lo que IHERING denominó efectos reflejos en las normas. DE CASTRO (4) nos dice que "desde IHERING se ha venido distinguiendo de los derechos subjetivos a las situaciones jurídicas protegidas sólo por el efecto reflejo de las normas o del ordenamiento jurídico". De esta forma, la igualdad puede ser reconocida por el legislador como concreción de un principio dimanante del ordenamiento jurídico, $y$ en esa medida dar lugar a situaciones de protección jurídica (p.180).

En este contexto, el espejismo de la igualdad no es otra cosa que la condición política global en la cual, las mujeres y los varones vienen creyendo que los sexos son iguales, que es cierto, que poseen las mismas determinaciones y las mismas oportunidades y por tanto, la situación actual es justa, y no necesita moverla hacia ninguna parte. Lo cual indica, que el reconocimiento de la igualdad de forma normativa nos puede llevar a creer que la mujer está protegida. Aunque realmente esta desprotegida debido a la falta de una igualdad real.

\section{Principales problemas para alcanzar una igualdad real con equidad de género en el derecho penal}

I. factores que inciden en la desigualdad de género en el derecho penal nicaragüense

Cuando hablamos de igualdad, inmediatamente viene a nuestra mente igualdad de razas, igualdad de sexos, que no son únicas, pero son una preocupación latente por forman parte de la vida cotidiana, pero también forma parte de nuestra vida cotidiana la violencia contra la mujer proveniente de la desigualdad por el patriarcado que persiste en nuestra sociedad y que aún mantiene a la mujer sometida y anulada en sus derechos. Por muchos textos legales, charlas escolares, discursos legislativos acerca de la erradicación de la violencia, la verdad pura y simple es que la violencia se mantiene latente, la verdad es que el machismo y el sistema patriarcal es un problema socio cultural que se mantiene incólume en la sociedad y representa unos de los principales obstáculos para alcanzar una igualdad real con equidad de género.

El hombre ha infravalorado a la mujer basándose en el poder físico y muchas veces económico por encima de la mujer, considerándolas como cero a la izquierda, sometiéndolas a trabajos de amas de casa y asignándoles solo a ellas el rol de cuidar a los hijos. Así, por ejemplo, Podemos ver los Juzgados Locales y Especializados en Violencia de género contra la mujer, atascados de acusaciones por Incumplimiento de deberes alimenticios, poniendo a la mujer en condición de mendicidad. A esto llamo discriminación indirecta, porque aunque el delito tiene como consecuencia un sanción penal privativa de libertad para el condenado, la madre de los hijos no tiene interés en una pena de esa naturaleza, sino el pago efectivo (en dinero o bienes) para la manutención de sus hijos.

En muchos casos los acusados (hombres) ni siquiera acuden al llamamiento judicial provocando un estado de rebeldía para no pagar los alimentos. Considero que esta es una forma de violencia y de discriminación hacia la mujer y hacia los hijos.

Hoy en día las mujeres siguen luchando por una igualdad material, las movilizaciones feministas buscan que la mujer en el plano de igualdad puede ejercer o lograr una autonomía propia en todos los ámbitos de su vida, sobre su economía, familia y cuerpo, sin impedimento de ningún tipo.

\section{Resultados y aportes}

La legislación nicaragüense reconoce constitucionalmente el derecho de igualdad y no discriminación como un derecho fundamental de todos, retomado en la Ley $\mathrm{N}^{\circ} 779$. 
De tal manera que Nicaragua reconoce un principio de igualdad formal, sin embargo el principal obstáculo que presenta este principio es el reconocimiento de la igualdad material, real o estructural. Es en este punto donde el ejercicio jurisdiccional a cargo de jueces y tribunales en materia de violencia de género, carecen de interpretación cuando de aplicar igualdad y equidad de género se trata.

El texto constitucional pierde efectividad al considerarse que la igualdad en el proceso penal es otorgar igualdad de oportunidades e intervenciones y alegatos a las partes en el proceso como muchos abogados y jueces suelen interpretarlos y no desde las condiciones en que se encuentra la mujer con relación al hombre en el proceso.

La repercusión social de las desigualdades se asienta sobre múltiples actos discriminatorios contras las mujeres como la falta de sensibilización, la falta de una fórmula que permita al juzgador poder establecer la igualdad real entre hombres y mujeres.

Otro problema es la falta de argumentación para considerar tratos desiguales en el proceso penal, ya que muchas veces para que prevalezca la igualdad deben darse un trato desigual, lo cual sería negativo si el judicial no justifica este trato diverso o desigual.

Los jueces y tribunales al tratarse de una igualdad real deben considerar el trato igual a los iguales y el trato desigual a los desiguales. Para llegar a considerar esto deben entonces proceder a realizar juicios de valor que no son más que un análisis de las condiciones socio-culturales, jurídicas y psicológicas en que se encuentra la mujer víctima de violencia en el proceso penal con relación a los hombres.

\section{Recomendaciones}

I) Eliminar los obstáculos que persisten en la desigualdad de las mujeres en el proceso penal nicaragüense aplicando una igualdad real, estructural y material. Para ello, deben diseñarse planes y programas de capacitación, formación inicial, continua y especializada con perspectiva de género e interculturalidad, derechos humanos, en materia constitucional, derechos de los pueblos indígenas y afro-descendientes, violencia, buen trato, comunicaciones y relaciones interpersonales, sometidos a una evaluación del desempeño a fin fortalecer el sistema de justicia penal en materia de violencia de género.

2) Los jueces deben aplicar un trato igual a los iguales y trato desigual a los desiguales, considerando una perspectiva de género. Por lo tanto, debe especializarse a jueces y funcionarios vinculados a la investigación, acusación y juzgamiento de delitos vinculados a la violencia de género en derecho con perspectiva de género y derechos humanos y derecho constitucional, mediante estudios superiores a nivel de postgrado, tales como: especializaciones, maestrías, doctorados (nacional o internacionales).

3) Promover investigaciones académicas en materia de violencia de género por parte del Instituto de Altos Estudios Judiciales en coordinación con universidades a fin de obtener un conocimiento integral sobre la violencia de género, concientización y sensibilización en esa materia.

4) Realizar un juicio de valor al momento de aplicar el principio de igualdad real y no discriminación, tomando en cuenta las condiciones y circunstancias en que se encuentra la víctima sobre todo la cronicidad de eventos de violencia y el menoscabo psicológico que le impiden estar en un plano de igualdad con el acusado en el proceso.

5) Que observatorio a cargo de la Corte Suprema de Justicia priorice conforme la política de Estado el reconocimiento, cumplimento y garantía de aplicación del principio de 
igualdad real con equidad de género en los proceso penales, promoviendo evaluación y seguimiento de las sentencias que vulneran el derecho de igualdad, a fin de examinar, corregir y mejorar los problemas de aplicación de la igualdad.

\section{Referencias Bibliográficas}

Alvar Muñoz, L., Robledo de Dios, T., Martos Navarro, F., \& Rodriguez Rivera Francisco Enrique. (2006). Evolución histórica de las iniciativas en materia de igualdad entre mujeres y hombre. Mecanismos institucionales para el logro de la igualdad. De la política social al mainstreaming. Integración de la perspectiva de género en la actividad de la Diputación Foral de Bizkaia. En L. Alvar Muñoz, T. Robledo de Dios, F. Martos Navarro, \& R. R. Enrirque, Administrativos de la Diputacion Foral de Bizkaia.temario. Volumen li.e-book. España: MAD,S.I.

Silva Charvet, E. (2005). Contexto histórico y conceptos políticos feministas.. En Silva Charvet, E. (Ed.). Identidad y Ciudadanía de las mujeres. Ecuador: Abya Yala. I I-54

Aráuz Ulloa, I. (1999). El principio de igualdad ante la ley. Encuentro. (No. 49). Año XXX. 3 I-37.

Astelarra, J. (2004). Políticas de género en la Unión Europea y algunos apuntes sobre América Latina. Mujer y Desarrollo, 57. Santiago de Chile.

Atienza, M. (2005). Las Razones del Derecho. Teorías de la Argumentación Jurídica. México: Unvirsidad Nacional Autónoma de Mexico.

Baño León, J. (1 987). La igualdad como derecho público subjetivo. Revista de Administración Pública (II4), 21.

Becerra Gelover, A., \& Rolander Garmendia, Y. (2006). El derecho a la no discriminación: una perspectiva internacional. El Cotidiano, 13.

Bautista, N. (2002). Capítulo I. Generalidades. En Bautista, N., Castillo, B., Nelson, M., Rodríguez, J. \& Perez Lora, F. . Aportes para la construcción de una jurisprudencia hacia la igualdad. Repúbllica Dominicana: Editora de Colores S.A. I I-34.

Cumbre Judicial Iberoamericana (2008) Reglas de Brasilia sobre el Acceso a la Justicia de las personas en condición de vulnerabilidad. Cancún: México.

Davis, A. (2004). Mujeres, raza y clase. Madrid, España: Akal S.A.

De Puelles Benites, M. (2102). Política, legislación y eduación. En M. DE PUELLES BENITES, Política, legislación y eduación (Pp. 120-122). España: UNED.

Díaz García, I. (2012). Igualdad en la Aplicación de la Ley. Concepto lusfundamentalidad y consecuencias. lus et Praxis, 76. Recuperado el 26 de Febrero de 2012, de http://www.scielo.cl/scielo.php?script=sci_arttext\&pid=S07 I 8-00 I 22012000200003

Esquembre Valdés, M. (2010). Género, ciudadanía y derechos. La subjetividad política y jurídica de las mujeres como clave para la igualdad efectiva. Anuario de derecho parlamentario. (No.

23). 47-85.

Fernéndez de Castro, P. (20I2). El camino hacia la transversalidad de género, el empoderamiento y la corresponsabilidad en las políticas de igualdad de género. Universitas. Revista de Filosofía, Derecho y Política. (No. 16). 79-104.

Ferrajoli, L. (1999). Derechos y garantías. La ley del más débil. En L. Ferrajoli. Madrid: Trotta.

Herranz Gómez, Y. (2006). Igualdad bajo sospecha. El poder transformador de la Educación. España: Narcea Ediciones.

Jellinek, G. (2000). Teoría general del Estado. Alemania: Fondo de Cultura Economica. 
Labiano Muñoz, A., Robledo de Diós, T., Martos Navarro , F., \& Rodríguez Rivera , F. (2006). Administrativos de la Diputacion Foral de Bizkaia. Temario. Volumen li.e-book. España: MAD-Eduforma.

Larrauri Pijoan, E. (2009). Igualdad y violencia de género: Comentario a la STC 59/2008. Revista para el Análisis del Derecho. (No. I). 2-17.

López Chocero, S. \& Sachis Vidal, A. (2016). Derecho y Principio de igualdad. En García Gil, C., Flecha García, C., Cala Carrillo, M. J., Nuñez Gil, M. \& Guil Bozal, A. (Coords.). Mujeres e Investigaciones Aportaciones interdisciplinares: VI Congreso Universitario Internacional "Investigación y Género". Sevilla: SIEMUS. 396-407.

Martínez, J., \& Zúñiga Urbina, F. (20II). El Principio de razonabilidad en la jurisprudencia del Tribunal Constitucional. Estudios constitucionales, 9(I), 199-226.

Texto de la Constitución Política de la República de Nicaragua con sus Reformas Incorporadas, Publicada en la La Gaceta Diario Oficial No. 32 martes 18 de Febrero de 2014. Nicaragua.

Pérez Portilla, K. (2002). Principio de igualdad: alcances y perspectivas. México, D.F.,: Instituto de Investigaciones Jurídicas - UNAM.

Sáez Carreras, J. (1998). El prisma del sexo. En J. Sáez Carreras (Coord.). El prisma del sexo. España: EDITUM.

Sala Franco, T., Ballester Pastor, M., Bañó León, J., Embid Irujo, J., \& Goerlich Peset, J. (2008). Comentarios a la Ley Orgánica 3/2007, de 22 de marzo, para la IGUALDAD EFECTIVA DE MUJERES Y HOMBRES. España: Wolters Kluwer España.

Sau Sánchez, V. (2000). ¿Qué es el feminismo?. En Gil Gómez, A., Sales Salvador, D., Sales, D. Mujeres: mediar para reconocer otros mundos en este mundo. España: Universitat Jaume I. 187-202.

Villlacorta Mancebo, L. (2006). Principio de igualdad y Estado social: apuntes para una relación sistemática. Catabria, España: Editorial Universidad de Cantabria.

Wallach Scott, J. (2008). Género e Historia. México, D. F.: Universidad Autónoma de México. 